Research Article

\title{
Assessment of psychosocial factors associated with relapse in patients with alcohol dependence: a retrospective observational study
}

\author{
Purshottam K. Kaundal $^{1}$, Indrajeet Sharma ${ }^{2} *$, Tulika Jha ${ }^{1}$
}

\begin{abstract}
${ }^{1}$ Department of Pharmacology, Indira Gandhi Medical College, Shimla-1, Himachal Pradesh, India

${ }^{2}$ Department of Pharmacology, AIMS, Rajsamand, Rajasthan, India

Received: 25 March 2016

Accepted: 27 April 2016

*Correspondence to:

Dr. Indrajeet Sharma,

Email: indi040787@gmail.com

Copyright: (C) the author(s), publisher and licensee Medip Academy. This is an openaccess article distributed under the terms of the Creative Commons Attribution NonCommercial License, which permits unrestricted noncommercial use, distribution, and reproduction in any medium, provided the original work is properly cited.
\end{abstract}

\begin{abstract}
Background: Alcohol in beverage form is among the most widely used psychoactive drugs in the world. Nonetheless, its complex pharmacologic actions, including panoply of psychoactive effects, have led societies throughout the world to surround alcoholic beverages with a variety of rules and regulations governing their use. Despite these efforts at control, excessive drinking, with its adverse effects are widespread.

Methods: It was a one year retrospective observational study. The sample consisted of fifty patients of alcohol dependence who following treatment for their condition had remained in a remitted state for at least four weeks, and had at least one relapse. The eligible patients fulfilling inclusion and exclusion criteria and giving written informed consent were enrolled into the study.

Results: Average time from treatment to lapse was $76.40 \pm 17.35$ days, while time taken from treatment to relapse was $138.40 \pm 31.38$ days. Average mean severity of alcohol dependence questionnaire score was $9.49 \pm 3.89$, the total score of relapse precipitant inventory was $15.94 \pm 3.86$, and the average value of coping behaviour inventory total score was $1.04 \pm 0.19$. On the presumptive stressful life events scale the total stress score was $200.84 \pm 17.78$. The selfefficacy scale (SES) of the patients, the average SES total scores was $60.10 \pm 8.77$.

Conclusions: Clinical parameters like number of previous relapses and positive family history of substance use emerged as significant determinants of relapse related psychosocial factors and appeared to be of greater importance in determining relapse.
\end{abstract}

Keywords: Alcohol, Psychosocial factors, Psychoactive effects, Relapse

\section{INTRODUCTION}

Alcohol abuse is an alcohol use disorder characterized by continued drinking despite negative consequences and the inability to fulfil responsibilities. Alcohol dependence, also known as alcoholism, is characterized by a craving for alcohol, possible physical dependence on alcohol, an inability to control one's drinking on any given occasion, and an increasing tolerance to alcohol's effects (DSM-V). ${ }^{1}$

Alcohol dependence is in general accepted as a psychiatric disorder with harmful physical, mental and social consequences and a high probability of a chronic relapsing course. It is considered a major public health problem in most societies. The view of addiction as a chronic relapsing disorder makes the prevention of relapse as one of the critical treatment elements for both the clinician and the consumer. ${ }^{2}$

In India prevalence of alcohol abuse is high in lower and lower middle sections of the society and among lesser educated. General population studies conducted in different parts of India suggest prevalence rates of use of alcoholic beverages ranging from $23 \%$ to $74 \%$ in males. Women constitute over $90 \%$ of abstainers, though among tribal groups and tea plantation workers, there are a substantial number of alcohol users in women, with prevalence rates ranging from $28 \%$ to $48 \%$. India is likely to face the heavy burden of medical and social problems due to increased alcohol consumption. ${ }^{3}$ 
Alcohol use disorders develop against a genetic, psychosocial and environmental background. Life-time prevalence estimates for all alcohol use disorders in the general population in Europe range from 12 to $24 \% .^{4}$ The prevalence of alcohol dependence was estimated to be 5$6 \%$ in men and $1-2 \%$ in women in Europe; however, the number of alcohol dependent women has been increasing recently. Relapse appears to remain the norm rather than the exception in substance use disorders treatment. Although widely researched for an extensive period of time, little is actually known and documented about the exact causes of relapse. Even less is known about the effect of personal and demographic contributors to relapse. $^{4}$

In the present study we had examined the association between demographic variables, clinical parameters, relapse precipitants, coping strategies, self-efficacy, stressful life events, perceived social support and relapse among patients with alcohol dependence.

\section{METHODS}

\section{Study design and set up}

The study was conducted at Indira Gandhi Medical College, Shimla, India which is a tertiary care centre of Himachal Pradesh from July 2014 to June 2015, located in North India and caters to the majority of population of the state. It was a retrospective observational study.

\section{Study population and selection process}

Patients with alcohol dependence syndrome attending out-patient department (OPD) and in-patient department (IPD) services were screened for enrolment in the study. Study included fifty patients of alcohol dependence syndrome with relapse. The sample consisted of fifty patients of alcohol dependence who following treatment for their condition had remained in a remitted state for at least four weeks, and had at least one relapse. The eligible patients fulfilling inclusion and exclusion criteria after obtaining written informed consent were enrolled in the study. In the present study relapse was defined as reemergence of alcohol dependence syndrome as per international classification of disease tenth revision (ICD-10) (WHO-1992) diagnostic criteria after a period of abstinence of at least one month. ${ }^{5}$ An inclusion criterion included; patients within the age range of 18-65 years, fulfilling the criteria for alcohol dependence as per ICD-10, remaining abstinent for at least 4 weeks in the past with or without treatment, having at least one relapse and showing willingness to participate in the study. An exclusion criterion included; patients with any comorbid psychiatric and/or personality disorder(s), patients having major physical illnesses, organic brain syndrome or mental retardation and patients with multiple substance abuse/dependence except for nicotine dependence.

\section{Baseline data collection}

All eligible patients had signed written informed consent form before participating in the study. Assessments were done when patients were in sober state.

A detailed history from the patient and/or a reliable person who knew the patient well was taken as per a predesigned recording format. Socio-demographic and clinical data was obtained from patients, family members, or relatives and recorded using self-devised semistructured proforma. After history and examination, subjects were assessed by using severity of alcohol dependence questionnaire (SADQ), relapse precipitant inventory (RPI), coping behaviour inventory (CBI), selfefficacy scale (SES), presumptive stressful life events scale (PSLES), social support questionnaire (SSQ), health promoting lifestyle profile scales II (HPLP II). Routine blood investigations like Hb, TLC, DLC, ESR, and blood sugar were carried out. Other relevant investigation like CT Head, thyroid function test etc. were done if needed.

\section{Statistical analysis}

In the study various sociodemographic and drug related variables were compared using appropriate statistical methods. The categorical and continuous variables were reported as percentages and mean \pm standard deviation, respectively. 2 tailed value of $<0.05$ was taken as statistically significant. Data was analysed using statistical software Epi Info version 3.4.3.

\section{RESULTS}

Baseline clinical characteristics of the study groups: Table 1 describes the distribution of socio-demographic characteristics of the study population under observation;

\section{Clinical profile of the patients}

\section{Age at initiation of alcohol intake}

The age of initiation of alcohol consumption was assessed using the definition described by Grant et al. ${ }^{6}$ which defines the age of initiation, as the "age at which they first started drinking, not counting small tastes or sips of alcohol." $70 \%$ of our patients initiated alcohol drinking between 14-25 years. The mean age of starting alcohol consumption was $22.96 \pm 7.08$ years.

\section{Duration of alcohol intake}

Mean duration of alcohol use in our study was $10.32 \pm 2.48$ years and $52 \%$ were consuming alcohol for $7-10$ years.

\section{Family history of alcohol use}

Family history of alcohol use was evaluated in parents and grandparents only. Family history of alcohol use disorder was found in $56 \%$ of patients. 


\section{Family history of alcohol dependence}

In the present study, around $52 \%$ patients had a family history of alcohol dependence.

Time to develop dependence and duration of alcohol dependence

In our study, average time to develop alcohol dependence was $4.98 \pm 1.42$ years and the average duration of alcohol dependence was $5.26 \pm 1.15$ years.

\section{No. of previous relapses}

In the present study, $56 \%$ patients had one relapse and $44 \%$ patients had two relapses in the past. The average of relapses was $1.44 \pm 0.50$.

\section{Relapse profile of patients with alcohol dependence}

In our study, average time from treatment to lapse was $76.40 \pm 17.35$ days, while time taken from treatment to relapse was $138.40 \pm 31.38$ days. Average time taken by the patients to develop relapse was $82.40 \pm 16.35$ days, while average time taken by the patients to seek help after relapse was $420 \pm 119.31$ days. Severity of alcohol dependence questionnaire scores (SADQ). Average mean SADQ score was $9.49 \pm 3.89$.

\section{Relapse precipitant inventory scores (RPI)}

In our study, the scores of relapse precipitant inventory, the mean value of negative mood states were $7.92 \pm 1.90$, External situations/euphoric states were $4.04 \pm 1.02$, lessened cognitive vigilance were $2.10 \pm 0.54$ and RPI total score was $15.94 \pm 3.86$.

\section{Scores on the coping behaviour inventory $(C B I)$}

In the present study, on the coping behaviour inventory, mean value of patient's positive thinking was $0.84 \pm 0.17$, negative thinking was $0.98 \pm 0.04$, avoidance was $1.60 \pm 0.49$, and the mean value of patients seeking social support was $1.54 \pm 0.50$. The average value of the CBI total score was $1.04 \pm 0.19$.

\section{Scores on the self-efficacy scale (SES)}

In our study, on the self-efficacy scale of the patients, general self-efficacy score was $39.20 \pm 8.47$, social selfefficacy score was $12.00 \pm 2.01$ and the average SES total scores was $60.10 \pm 8.77$.

Scores on the presumptive stressful life events scale (PSLES):

On the presumptive stressful life events scale, average score of desirable events was $0.87 \pm 0.10$, undesirable events was $0.80 \pm 0.09$, total events was $5.00 \pm 1.06$, and the total stress score was $200.84 \pm 17.78$. The lifetime stress score of the patients was $390.20 \pm 35.25$.

Table 1: Socio-demographic characteristics of the patients.

\begin{tabular}{|lc|}
\hline Variables & No. of patients (percentage) \\
\hline Age (years) (Mean \pm SD) & $43.66 \pm 6.23$ \\
\hline Sex & $100 \%($ male) \\
\hline Rural/Urban & $38(76.0 \%)$ \\
\hline Rural & $12(24.0 \%)$ \\
\hline Urban & $7(14.0 \%)$ \\
\hline Marital status & $42(84.0 \%)$ \\
\hline Single & $1(2.0 \%)$ \\
\hline Married & \\
\hline Divorced & $37(74.0 \%)$ \\
\hline Type of family & $13(26.0 \%)$ \\
\hline Nuclear & $1(2.0 \%)$ \\
\hline Joint & $18(36.0 \%)$ \\
\hline Education & $31(62.0 \%)$ \\
\hline Illiterate & \\
\hline Matriculate & $3(6.0 \%)$ \\
\hline Graduate & $10(20.0 \%)$ \\
\hline Occupation & $30(60.0 \%)$ \\
\hline Unemployed & $7(14.0 \%)$ \\
\hline Govt. employee & $11(18.3 \%)$ \\
\hline $\begin{array}{l}\text { Self-employed/ } \\
\text { Businessman }\end{array}$ & $12(20.3 \%)$ \\
\hline Farmer & \\
\hline Socioeconomic status modified Kuppuswamy's scale \\
\hline Upper & 0 \\
\hline Upper middle & \\
\hline Lower middle & \\
\hline Upper lower & \\
\hline Lower & \\
\hline
\end{tabular}

Table 2:Clinical profile of the patients.

\begin{tabular}{|ll|}
\hline \multicolumn{2}{|l|}{$\begin{array}{c}\text { Alcohol related variables } \\
\text { Nof patients } \\
\text { (percentage) }\end{array}$} \\
\hline $\begin{array}{l}\text { Age of initiation of alcohol intake } \\
\text { (years) (Mean } \pm \text { SD) }\end{array}$ & $22.96 \pm 7.08$ \\
\hline $\begin{array}{l}\text { Duration of alcohol intake (years) } \\
\text { (Mean } \pm \text { SD) }\end{array}$ & $10.32 \pm 2.48$ \\
\hline Family history of Alcohol use & $28(56.0 \%)$ \\
\hline Present & $22(44.0 \%)$ \\
\hline Absent & $26(52.0 \%)$ \\
\hline Family history of Alcohol dependence \\
\hline Present & $24(48.0 \%)$ \\
\hline Absent & $4.98 \pm 1.42$ \\
\hline Time to develop dependence (years) & $5.26 \pm 1.15$ \\
\hline Duration of alcohol dependence (years) & \\
\hline No. of previous relapses & $28(56.0 \%)$ \\
\hline 1 & $22(44.0 \%)$ \\
\hline 2 &
\end{tabular}


Scores on the social support questionnaire (SSQ)

Total SSQ scores in our study were 44.34 \pm 9.44 .

Scores on the health promoting lifestyle profile II (HPLP II)

Total HPLP II scores in our study were $26.56 \pm 4.23$.

Table 3: Relapse profile of patients.

\begin{tabular}{|ll|}
\hline Relapse variables (days) & (Mean \pm SD) \\
\hline Time from treatment to lapse & $76.40 \pm 17.35$ \\
\hline Time from treatment to relapse & $138.40 \pm 31.38$ \\
\hline Duration of relapse & $82.40 \pm 6.35$ \\
\hline Time taken to seek help after relapse & $420.00 \pm 119.31$ \\
\hline SADQ scores & $9.49 \pm 3.89$ \\
\hline
\end{tabular}

Table 4: Scores on the relapse precipitant inventory (RPI), coping behaviour inventory (CBI), self-efficacy scale (SES), presumptive stressful life events scale (PSLES), social support questionnaire (SSQ) and the scores on the health promoting lifestyle profile II (HPLPII).

\begin{tabular}{|ll|}
\hline \multicolumn{2}{|l|}{ Relapse precipitant inventory: } \\
\hline Negative mood states & $7.92 \pm 1.90$ \\
\hline External situations/ euphoric states & $4.04 \pm 1.02$ \\
\hline Lessened cognitive vigilance & $2.10 \pm 0.54$ \\
\hline RPI total score & $15.94 \pm 3.86$ \\
\hline Coping behaviour inventory: \\
\hline Positive thinking & $0.84 \pm 0.17$ \\
\hline Negative thinking & $0.98 \pm 0.04$ \\
\hline Avoidance & $1.60 \pm 0.49$ \\
\hline Seeking social support & $1.54 \pm 0.50$ \\
\hline CBI total score & $1.04 \pm 0.19$ \\
\hline Self-Efficacy Scale: & $39.20 \pm 8.47$ \\
\hline General self-efficacy & $12.00 \pm 2.01$ \\
\hline Social self-efficacy & $60.10 \pm 8.77$ \\
\hline SES total scores & \\
\hline $\begin{array}{l}\text { Presumptive stressful life events scale (stressful life } \\
\text { events for the past year): }\end{array}$ \\
\hline Desirable events & $0.87 \pm 0.10$ \\
\hline Undesirable events & $0.80 \pm 0.09$ \\
\hline Total events & $5.00 \pm 1.06$ \\
\hline Total stress score & $200.84 \pm 17.78$ \\
\hline Lifetime stress score & $390.20 \pm 35.25$ \\
\hline Total SSQ scores & $44.34 \pm 9.44$ \\
\hline HPLP II score & $26.56 \pm 4.23$ \\
\hline
\end{tabular}

\section{DISCUSSION}

In the present study, mean age of the patients was $43.66 \pm 6.23$ and $68 \%$ of the patients were more than 40 years old. There was no female patient, this probably reflects that female drinking is less prevalent in this region and appears to be culturally unacceptable practice. It is also possible that due to stigma attached to female alcohol consumption (a cultural factor) less number of female patients must be visiting general hospital setting for treatment. ${ }^{7-10}$ The present study showed that certain clinical and psychosocial variables were reliably and consistently associated with relapse among patients with alcohol dependence. Thus, it adds to the previous research in this area which has demonstrated that similar clinical/social variables are important correlates of relapse. Consequently, clinical parameters such as the number of previous relapses and positive family history of substance use emerged as determinants of relapse among patients with alcohol dependence, while a shorter time to dependence was associated with relapse among patients of alcohol dependence. These observations are in line with previous suggestions that severity/outcome of substance dependence could be one of the important correlates of relapse. ${ }^{11,13-15}$ At the same time, psychosocial factors such as relapse precipitants (or high risk situations), coping, self-efficacy and stressful life events appeared to be of greater importance in determining relapse. Patients who had relapsed were more likely to have been exposed to a higher total number of high risk situations. These results are not only consistent with proposals regarding the pivotal role of exposure to high risk situations in the onset of relapse, but also in accordance with the results of a number of earlier studies. ${ }^{11,15-19}$ Patients with alcohol dependence who remained abstinent tended to use more number of coping strategies including adaptive strategies such as 'positive thinking', while those who had relapsed used maladaptive strategies such as 'negative thinking' more often. It has been reported previously that the number and effectiveness of coping strategies among patients are important in determining relapse. ${ }^{11,13,15,20}$

Furthermore, patients who had relapsed in this study had experienced a higher number of undesirable life events, which is in line with some of the earlier studies which have documented such an association. ${ }^{11,21-23}$ In addition, the current study extends the results regarding correlates of relapse further by demonstrating the operation of largely similar mechanisms of relapse among patients with alcohol dependence. This is noteworthy because there is paucity of literature on research on relapse among patients with alcohol problems in our region which is addressed only occasionally. Finally, the models of relapse referred to earlier have been developed in the west and much of the research evidence also originated from the Western countries. ${ }^{11,17,23-25}$

Thus, the present findings are useful in illustrating the universal nature of relapse in substance dependence and its proposed mechanisms. If the variables identified in the current and earlier studies are indeed important correlates of relapse in substance dependence, these could be of considerable help not only in predicting relapse, but also 
in identifying key areas to be targeted in order to prevent this common and distressing occurrence.

In the present study we may conclude that there is significant association of relapse among patients with alcohol dependence syndrome with demographic and psychosocial variables. Clinical parameters such as the number of previous relapses and positive family history of substance use emerged as significant determinants of relapse psychosocial factors such as relapse precipitants (or high risk situations), coping behaviour, self-efficacy and stressful life events appeared to be of greater importance in determining relapse.

Due to a small sample size, the findings of this study need to be corroborated in larger sample studies. History of alcohol use was based as reported by patient/family member. Factor of recall bias cannot be ruled out. The study was a retrospective observational one. A prospective study design should be planned to see the association between demographic and psychosocial variables with relapse.

Funding: No funding sources

Conflict of interest: None declared

Ethical approval: Not required

\section{REFERENCES}

1. American Psychiatric Association: Diagnostic and statistical Manual of Mental Disorder, Fifth Edition, DSM-5TM. Washington, DC, American Psychiatric Association, 2013.

2. Ait-Daoud N, Malcolm RJJr, Johnson BA. An overview of medications for the treatment of alcohol withdrawal and alcohol dependence with an emphasis on the use of older and newer anticonvulsants. Addictive Behaviors. 2006;31:1628-49.

3. Deb PC, Jindal BR. Drinking in rural areas. Study in selected villages of Ludhiana, Punjab, India. Monograph, Punjab Agri. Univ. Ludhiana. (1975).

4. Anton RF, O'Malley SS, Ciraulo DA, Cisler RA, Couper D, Donovan DM, et al. Combined pharmacotherapies and behavioral interventions for alcohol dependence: the Combine study: a randomized controlled trial. J Am Med Asso. 2006;295(17):2003-17.

5. World Health Organization. The ICD-10 Classification of Mental and Behavioural Disorders: Clinical descriptions and diagnostic guidelines, Geneva: WHO. Mental and behavioural disorders due to psychoactive substance use. 1992 .

6. Grant BF. The impact of a family history of alcoholism on the relationship between age at onset of alcohol use and DSM-IV alcohol dependence: Results from the National longitudinal alcohol epidemiologic survey. Alcohol Health Res World. 1998;22:144-7.
7. Ministry of Health and Family Welfare. MOHFW: National Family Health Survey 3.Available at www. rchiips. org / NFHS/ index.html. Accessed 24 August 2015.

8. Sarkar AP, Sen S, Mondal S, Singh OP, Chakraborty A, Swaika B. A study on sociodemographic characteristics of alcoholics attending the deaddiction center at Burdwan Medical College and Hospital in West Bengal. Indian J Pub Health. 2013;57(1):33-5.

9. WHO India. Current patterns and trends of alcohol abuse. Available at http:// www.whoindiaorg / Linksfiles/ Mental Health and substance abuse alcohol atlas4 pdf 2011. Accessed 22 August 2015.

10. Obot SI, Room R. Alcohol, Gender and drinking problems: perspectives from low and middle income countries. department of mental health and substance abuse. Geneva: World Health Organization; 2005.

11. Mattoo SK, Chakrabarti S, Anjaiah M. Psychosocial factors associated with relapse in men with alcohol or opioid dependence. Indian $\mathrm{J}$ Med Res. 2009;130:702-8

12. Marlatt GA, Gordon JR. Relapse prevention. Maintenance strategies in addictive behavioural change. New York: Guilford Press;1980:152-60.

13. Litman GK, Eiser JR, Rawson JCB, Oppenheim AN. Differences in relapse precipitants and coping behaviour between alcohol relapsers and survivors. Behav Res Ther. 1979;17:89-94.

14. Mattoo SK, Basu D. Malhotra A, Malhotra R. Relapse precipitants, life events and dysfunctions in alcohol and opioid dependent men. Indian J Psychiatry. 2003;45:39-44.

15. Singh NH, Sharma SG, Pasweth AM. Psychiatric comorbidity among alcohol dependents. Indian J Psychiatry. 2005;47:222-4.

16. Mattoo SK, Malhotra R. Relapse precipitant inventory: hindi adaptation and factor structure. Indian J Clin Psychol. 2000;27:278-85.

17. Litman GK, Stapelton J, Oppenheim AN, Peleg M. An instrument for measuring coping behaviours in hospitalised alcoholics: implications for relapse prevention treatment. Br J Addict. 1983;78:269-79.

18. Mattoo SK, Malhotra R. Self-efficacy scale. Hindi translation and factor structure. Indian $\mathbf{J}$ Clin Psychol. 1998;25:154-8.

19. Singh G, Kaur D, Kaur H. Presumptive stressful life events scale for use in India. Indian J Psychiatry. 1984;26:107-14.

20. Singhal S, Nagalakshmi SV, Singhal S. Relapse in alcoholism: psychosocial study. Nimhans J. 1992:47-9.

21. Maisto SA, O'Farrell TJ, Connors GJ, Mckay JR, Pelcovits M. Alcoholics' attributions of factors affecting their relapse to drinking and reasons for terminating relapse episodes. Addict Behav. 1988;13:79-82.

22. Burling TA, Reilly PM, Moltzen JO, Ziff DC. Selfefficacy and relapse among inpatients with drug and alcohol abuse. J Stud Alcohol. 1989;5:354-60. 
23. Mckay JR, Maisto SA, O'Farrell TJ. End-of treatment self-efficacy, aftercare and drinking outcomes of alcoholic men. Alcohol Clin Exp Res. 1993; $17: 1076-83$.

24. Marlatt GA. Taxonomy of high-risk situations for alcohol relapse: evolution and development of a cognitive-behavioural model. Addiction. 1996;91(1):37-50.

25. Finney JW, Moos RH, Mewborn CR. Post-treatment experiences and treatment outcome of alcoholic patients six months and two years after hospitalization. J Consult Clin Psychol. 1980;48:17-29.

Cite this article as: Kaundal PK, Sharma I, Jha T. Assessment of psychosocial factors associated with relapse in patients with alcohol dependence: a retrospective observational study. Int J Basic Clin Pharmacol 2016;5:969-74. 